\title{
REVIEWS
}

\section{Use of the diagnostic bacteriology laboratory: a practical review for the clinician}

\author{
W J Steinbach, A K Shetty
}

Lucile Salter Packard Children's Hospital at Stanford, Stanford University School of Medicine, 725 Welch Road, Palo Alto, California, USA 94304, USA

W J Steinbach

A K Shetty

Correspondence to:

Dr Steinbach

md.stewi@lpch.stanford.edu

Submitted 27 March 2000 Accepted 5 June 2000

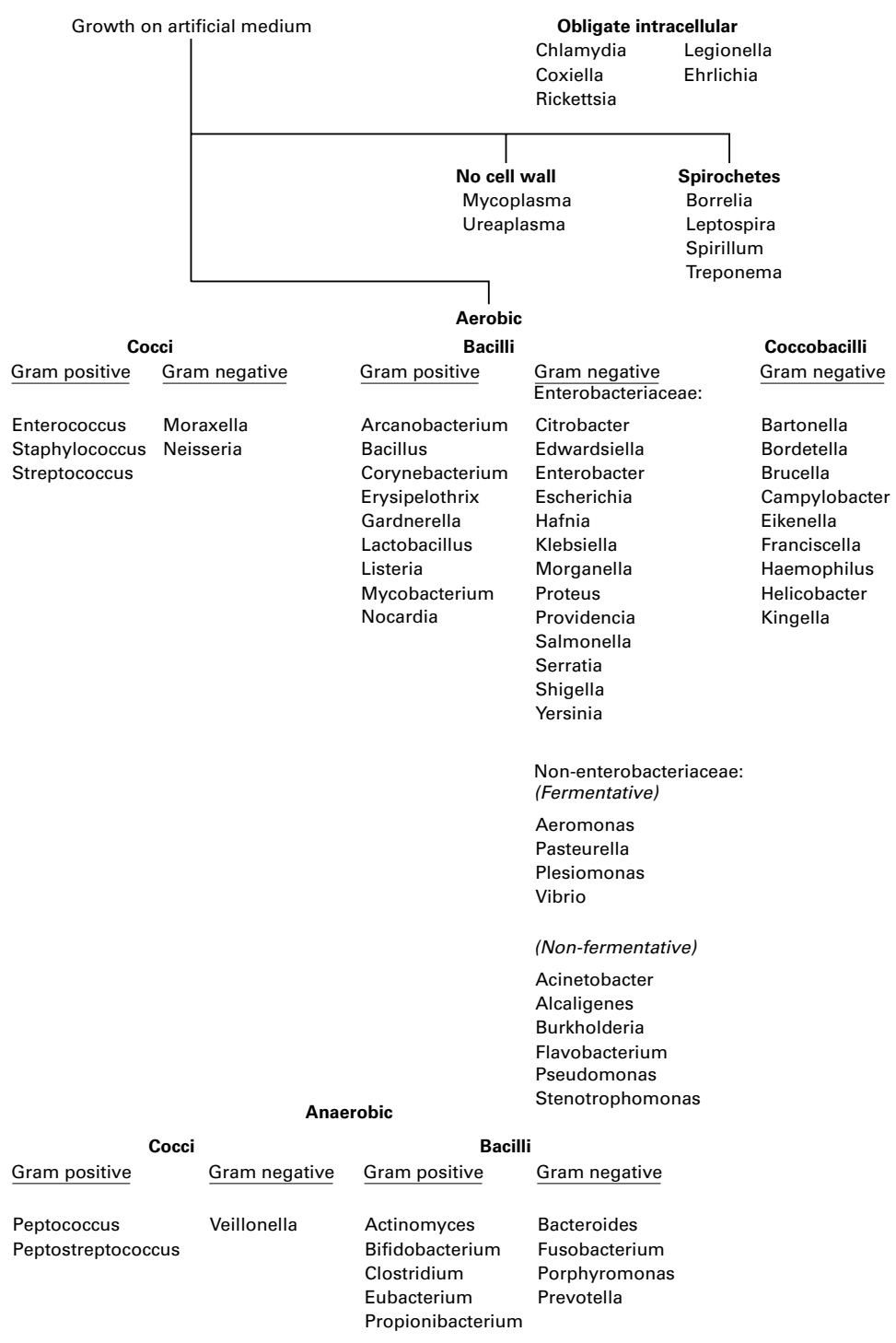

Figure 1 Classification of clinically significant bacteria by genus.

Effective utilisation and understanding of the clinical bacteriology laboratory can greatly aid in the diagnosis of infectious diseases. Although described more than a century ago, the Gram stain remains the most frequently used rapid diagnostic test, and in conjunction with various biochemical tests is the cornerstone of the clinical laboratory. First described by Danish pathologist Christian Gram in $1884^{12}$ and later slightly modified, the Gram stain easily divides bacteria into two groups, Gram positive and Gram negative, on the basis of their cell wall and cell membrane permeability to

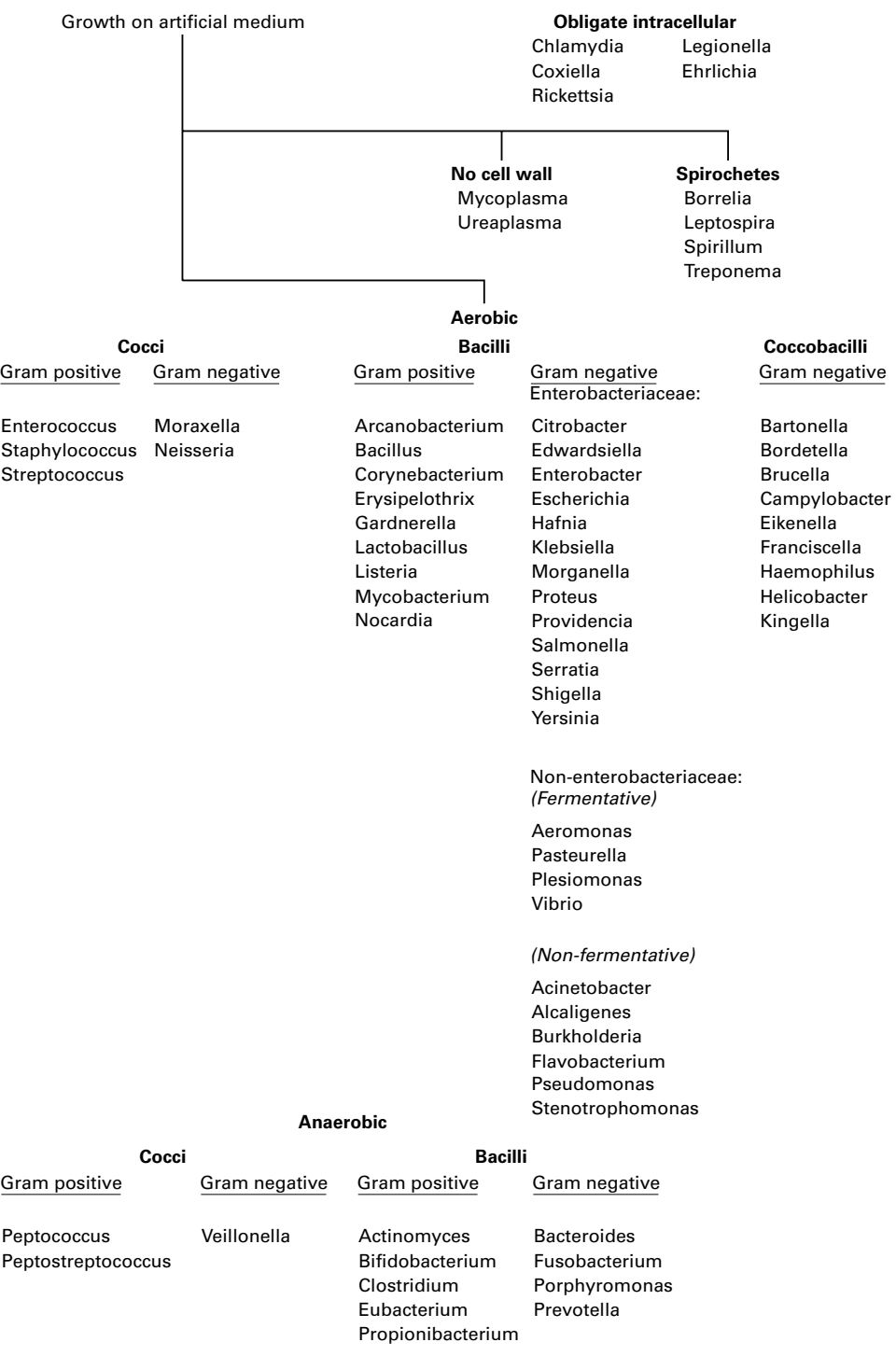

\author{
Box 1: Gram stain technique \\ (1) Air dry specimen and fix with \\ methanol or heat. \\ (2) Add crystal violet stain. \\ (3) Rinse with water to wash unbound \\ dye, add mordant (for example, iodine: \\ potassium iodide). \\ (4) After waiting 30-60 seconds, rinse with \\ water. \\ (5) Add decolorising solvent (ethanol or \\ acetone) to remove unbound dye. \\ (6) Counterstain with safranin. \\ Gram positive bacteria stain blue \\ (retained crystal violet). \\ Gram negative bacteria stain red \\ (decolorised and then counterstained).
}

organic solvents (box 1)..$^{3-5}$ Information derived from a Gram stain and several simple biochemical tests can be enormous, often providing a presumptive diagnosis and significantly influencing patient care. Unfortunately the training for correctly interpreting the Gram stain is disappearing. ${ }^{6}$ The goal of this article is to review the utility of the clinical bacteriology laboratory and discuss its role in the diagnosis of common clinical pathogens.

\section{Gram stain basics}

The Gram stain classifies bacteria (fig 1) phenotypically based on differences in cell wall thickness with differing glycosaminopeptide and lipoprotein compositions: Gram positive bacteria have a peptidoglycan layer 10-15 times thicker than Gram negative bacteria. The cell wall, synonymous with the peptidoglycan layer, is a rigid framework of cross linked peptidoglycan forming the outermost component of the cell. The more complex Gram negative bacteria also have an outer membrane beyond the peptidoglycan layer that consists of lipopolysaccharide (endotoxin), lipoprotein, and phospholipids. In some Gram negative species there also exists a periplasmic space between the outer membrane and the inner cytoplasmic membrane with $\beta$-lactamases that degrade $\beta$-lactam antibiotics.

The present hypothesis for the mechanism of the Gram stain states the cell wall acts as a physical permeability barrier restricting diffusion of the stain complex, ${ }^{7}$ and any microorganism with a cell wall able to retard the efflux of the crystal violet-iodine complex 
should be Gram positive. The mechanism further implies that solvent decolorisation causes significant damage to the cell surfaces of Gram negative bacteria, and only limited damage to Gram positive bacteria. This suggests Gram negative bacteria are more "leaky", causing these thin walled lipid-rich cells to lose their crystal violet stain and appear red from the counterstain. Gram positive cells, thick walled and lipid-poor, appear blue from retaining the original crystal violet.

\section{Gram stain utility}

Gram stain interpretation gives immediate information regarding the presence or absence of bacterial disease and can guide initial antibiotic treatment. Additionally, epithelial and inflammatory cells are stained in a Gram stain, thus providing information about the host immune response and quality of the specimen. A well prepared sample can showcase the organism's colour, size, shape, and arrangement, allowing cellular morphology to further separate bacteria into four major groups. Cocci are spherical or oval, bacilli are rod-like or cylindrical, vibrios are comma-like or curved, and spirochetes are flexible (spirilla if rigid) and helical. Additionally, coccobacilli are unusually short bacilli, and fusiform bacilli are bacilli with tapered ends.

\section{Limitations}

Several substances have been shown to convert Gram staining results. Ultraviolet light, antibiotics, prolonged heat fixation, crushing of unprotected cells on a slide, or autolysis by enzymes such as ribonucleases or lysozymes have all been shown to cause Gram positive
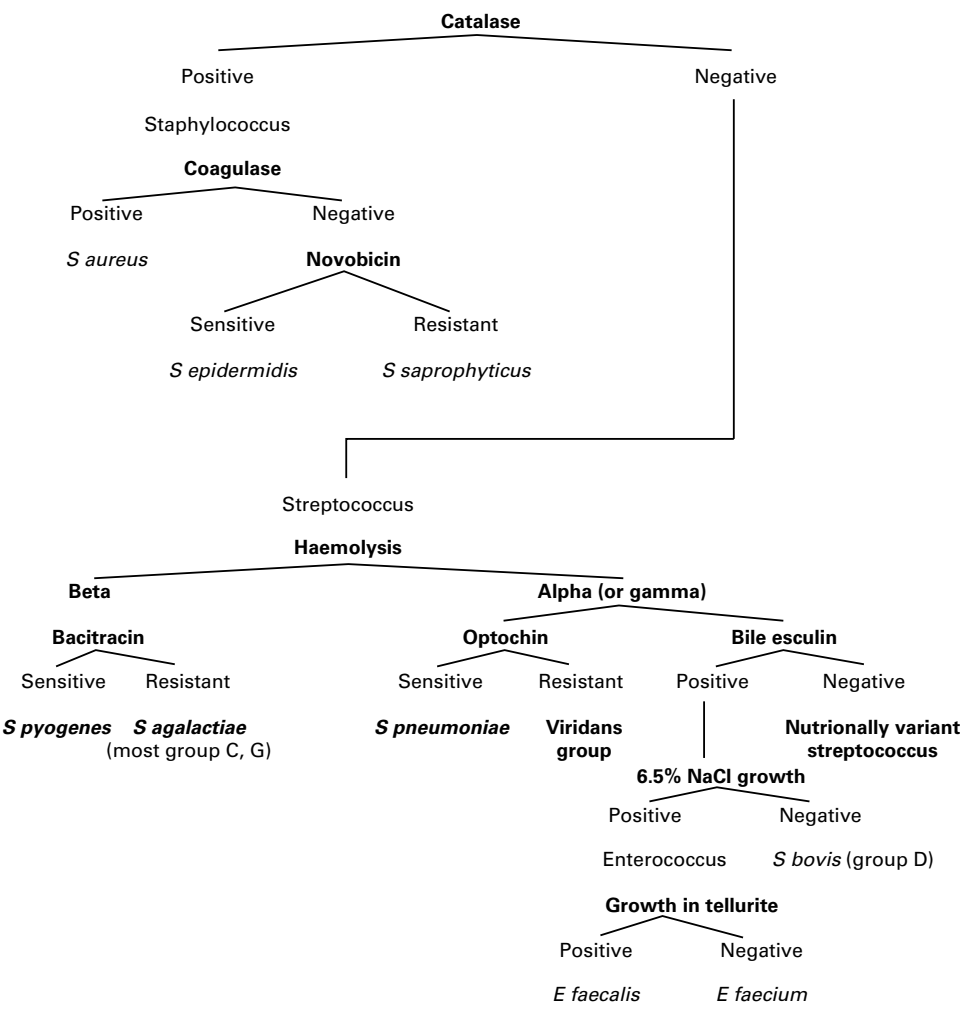

Figure 2 Differentiating aerobic Gram positive cocci. cells to stain Gram negatively. The age of the culture also influences the degree of Gram positivity, with cells 48 hours old sometimes more Gram positive than younger cells.

Several bacteria are unable to be Gram stained for a variety of reasons. Mycobacteria and nocardia have a high concentration of lipids called mycolic acids in their cell walls and are "acid-fast" because they resist decolorisation with an organic solvent. The spirochetes (treponema, borrelia, leptospira, spirillum) are too thin and are best seen with darkfield microscopy. Legionella, rickettsia, coxiella, ehrlichia, and chlamydiae are primarily intracellular and although possess outer and inner membranes similar to Gram negative bacteria, lack a peptidoglycan layer to take up a Gram stain adequately. Mycoplasma and ureaplasma do not have a cell wall to absorb the stain.

\section{Specific bacteria}

\section{GRAM POSITIVE COCC}

The two principal medically important genera are staphylococcus and streptococcus, arranged in irregular grapelike clusters and chains, respectively (fig 2). The orientation and degree of attachment at the time of cell division determines the type of arrangement: staphylococci divide in three planes while streptococci divide in only one plane. Enterococci are closely related to the streptococci yet are now known to be phylogenetically distinct and therefore comprise their own genus. The enzyme catalase, which degrades hydrogen peroxide to oxygen and water, differentiates catalase positive staphylococci from catalase negative streptococci and enterococci.

\section{STAPHYLOCOCCI}

Staphylococci are a major component of the normal human flora and the presence of coagulase, which accelerates the formation of a fibrin clot from fibrinogen, differentiates the species. Although there are 29 species of coagulase negative staphylococci, most clinical isolates are either Staphylococcus epidermidis or Staphylococcus saprophyticus. Staphylococcus epidermidis is part of the normal skin flora. Although often occurring as a contaminant in blood culture specimens, $S$ epidermidis may cause infection in neonates, the immunocompromised, and in patients with an indwelling central line, shunt placement, or prosthetic implant. Staphylococcus saprophyticus occurs chiefly in the periurethral and urethral flora where it shows a tropism for urinary tract epithelium and causes urinary tract infections in sexually active adolescent girls, second only to Escherichia coli in this age group. ${ }^{9}$

Staphylococcus aureus is an important pathogen, causing skin infections, osteomyelitis, pneumonia, and septicaemia. It is distinguished on the positive results of coagulase, mannitol fermentation, and deoxyribonuclease tests. ${ }^{10}$ Selective media, such as mannitol salt agar, may be used for isolating $S$ aureus when screening for carriage in infection control investigations. In the last decade the prevalence of resistance to penicillin $\mathrm{G}$ among isolates of $S$ aureus and $S$ epidermidis has consistently 
exceeded $90 \% .^{11}$ Resistance to penicillin $\mathrm{G}$ is due to the production of $\beta$-lactamases under the control of transmissible plasmids and can be overcome with $\beta$-lactamase resistant (second generation) penicillins, such as nafcillin or methicillin.

Since the first case reports of methicillin resistant $S$ aureus (MRSA) in the United States in 1968, MRSA has become an increasing problem. ${ }^{12}$ Several hospitals have reported methicillin resistance prevalence of $39 \%$ among $S$ aureus and $75 \%$ among $S$ epidermidis isolates, ${ }^{11}$ an example where Gram stain and biochemical differentiation can greatly influence antibiotic choice. Methicillin resistance to $S$ aureus is mediated by the chromosomal mecA gene, which encodes a novel altered penicillin binding protein (PBP-2A) that causes resistance to all $\beta$-lactam antibiotics, including cephalosporins. ${ }^{13}$ The recent identification of strains of $S$ aureus with intermediate level resistance to vancomycin has caused great concern because vancomycin is the drug of choice for MRSA. ${ }^{14}$

\section{STREPTOCOCCI}

Streptococci may be classified according to the type of haemolysis when cultured on blood agar, namely $\beta, \alpha$, or $\gamma$-haemolysis. $\beta$-Haemolysis refers to complete haemolysis of the sheep red blood cells in agar and therefore shows a clear zone around colonies due to the production of enzymes called haemolysins. $\alpha$-Haemolysis is an incomplete haemolysis producing a greenish discoloration around the colonies, while $\gamma$-haemolysis refers to nonhaemolysis. $\beta$-Haemolytic streptococci are further classified into Lancefield groups (A-H, $\mathrm{K}-\mathrm{V}$ ), based on the antigenic " $\mathrm{C}$ " carbohydrate in the cell wall and reactions to pools of antisera as originally described by Rebecca Lancefield. Groups A, B, C, D, and G are the groups most commonly associated with human infections.

Group A (Streptococcus pyogenes) streptococci, a pathogen responsible for a wide range of superficial and deep infections, are further classified into certain types according to the $M$ protein, an antiphagocytic fibrillar molecule that interferes with deposition of complement $\mathrm{C} 3 \mathrm{~b}$ on the streptococcal cell wall surface. ${ }^{15}$ Group A $\beta$-haemolytic streptococci antigen detection tests have been designed based on extraction of the group specific carbohydrate antigen followed by detection with an antibody tagged reagent to produce a colour change. Sensitivity ranges from $79 \%$ to $87 \%$; specificity ranges from $90 \%$ to $96 \% .^{16}$ No penicillin resistant group A $\beta$-haemolytic streptococcal strains have been identified. Although penicillin tolerance has been described, with decreased bacterial killing by growth inhibiting antibiotic concentrations, its clinical significance has not been defined. ${ }^{17}$

Group B (Streptococcus agalactiae) streptococci produce a narrow zone of $\beta$-haemolysis, and may be identified presumptively by a positive CAMP test. ${ }^{18}$ The organism is a major pathogen in neonatal sepsis, with increasing attack rates inversely related to birth weight. ${ }^{19}$
Capsular polysaccharides can be identified using an antigen latex particle agglutination test for the cerebrospinal fluid, serum, or urine. Group B streptococci as well as Listeria monocytogenes, both major neonatal pathogens, are treated with a penicillin while gentamicin is added in the nursery for Gram negative coverage, namely $E$ coli.

Group C streptococci species (chiefly Streptococcus equisimilis) are $\beta$-haemolytic and have been identified as a cause of pharyngitis but are not associated with non-supporative complications like rheumatic fever due to decreased virulence of the group specific carbohydrate compared to the M protein. Group G streptococci also produce a wide zone of $\beta$-haemolysis and occasionally cause cellulitis and bone and joint infections, often requiring the addition of an aminoglycoside with a penicillin for therapy.

Viridans streptococci derive their name from the Latin word viridis, a reference to the green colour seen in the $\alpha$-haemolysis, however some species are $\beta$ or $\gamma$-haemolytic. Viridans streptococci, the preferred term since "Streptococcus viridans" implies a single species and not a group of species, lack classic virulence factors possessed by other streptococci and therefore have a low pathogenic potential in the normal host. Viridans streptococci are ubiquitous inhabitants of the mouth and produce an extracellular dextran which may have a role in mediating bacterial adherence to heart valves in endocarditis. ${ }^{20}$ Viridans streptococci account for $40.3 \%$ of bacterial endocarditis cases while other bacteria account for a minority of cases: $S$ aureus $(23.8 \%), S$ epidermidis $(4.7 \%)$, and enterococci $(4.0 \%){ }^{21}$

Streptococci that grow in the intestine are now designated enterococci. Before recent reclassification raised enterococci to genus level, group D streptococci were divided into enterococcal species (chiefly Enterococcus faecalis, Enterococcus faecium) and non-enterococcal species (Streptococcus bovis) based on the differential ability of the enterococci to grow in hypertonic $6.5 \%$ saline solution. Most enterococci produce $\gamma$ or $\alpha$-haemolysis on blood agar and all are able to grow on MacConkey medium that contains bile salts. Most human clinical isolates are either $E$ faecalis (74-90\%) or E faecium $(5 \%-16 \%)^{22}$ and biochemical tests can further differentiate these two, important in planning therapy since $E$ faecium is more antibiotic resistant than $E$ faecalis. Enterococci are resistant to multiple drugs, including uniform resistance to cephalosporins, and empiric treatment requires a penicillin plus an aminoglycoside for synergy.

Streptococcus pneumoniae shows a characteristic diplococci on Gram staining and is consistently $\alpha$-haemolytic and optochin sensitive. $S$ pneumoniae possess a polysaccharide capsule which interferes with phagocytosis; this capsule can be made to swell for rapid identification (quellung reaction) and differentiation into one of more than 90 serotypes. Penicillin and cephalosporin resistant $S$ pneumoniae are emerging as a result of alterations in penicillin binding proteins. Because resistance is not a result of the production of $\beta$-lactamases, 


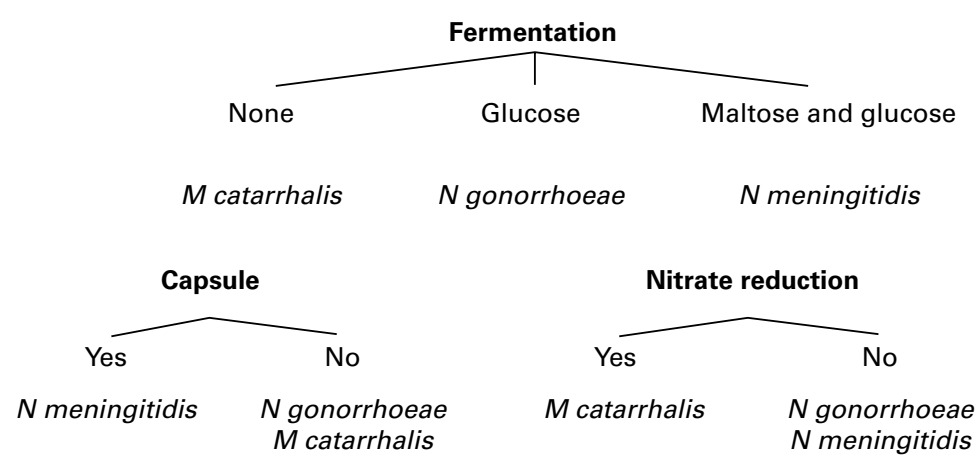

Figure 3 Differentiating aerobic Gram negative cocci.

antibiotics with $\beta$-lactamase inhibitors such as clavulonic acid are not helpful.

In recent years the proportion of penicillin non-susceptible pneumococcal invasive isolates has varied from $0 \%-41 \%{ }^{23}$ Of these isolates, $5 \%-21 \%$ exhibit penicillin resistance. The incidence of cefotaxime and ceftriaxone non-susceptible pneumococcal isolates has increased to $20 \%$ in some areas. The Streptococcus pneumoniae Therapeutic Working Group recently advocated using higher dose amoxicillin in less invasive infections, such as acute otitis media, to overcome penicillin binding protein resistance in high risk patients. ${ }^{24}$ The concern for resistance has also brought about the practice of simultaneously using vancomycin and a third generation cephalosporin, ceftriaxone or cefotaxime, as empiric coverage for meningitis due to suspected $S$ pneumoniae in patients beyond 3 months of age. Vancomycin addresses the possibility of cephalosporin resistance while a well absorbed cephalosporin compensates for the poor cerebrospinal fluid penetrability of vancomycin. ${ }^{25}$

GRAM NEGATIVE COCCI

There are three medically important Gram negative cocci (fig 3): Neisseria meningitidis, a

Spore forming

Yes No

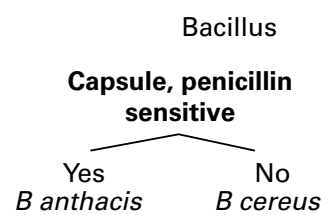

A haemolyticum
Corynebacterium
E rhusiopathiae
$G$ vaginalis
Lactobacillus
$L$ monocytogenes
Mycobacterium
Nocardia

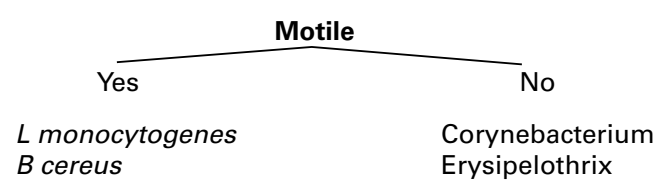

$\begin{array}{ll}\frac{\text { Haemolysis }}{\text { Gamma }} & \text { Beta } \\ \text { B anthracis } & \begin{array}{l}\text { A haemolyticum } \\ \text { B cereus } \\ \text { L monocytogenes }\end{array}\end{array}$

\begin{tabular}{ll}
\multicolumn{2}{c}{ Catalase } \\
Positive & Negative \\
Bacillus & A haemolyticum \\
$C$ diphtheriae & Erysipelothrix \\
$L$ monocytogenes & Lactobacillus
\end{tabular}

Figure 4 Differentiating aerobic Gram positive cocci. major cause of meningitis and sepsis, $N$ gonorrhoeae, the cause of gonorrhoea and pelvic inflammatory disease, and Moraxella catarrhalis (formerly Branhamella catarrhalis), which can cause respiratory infections including otitis media, sinusitis, and pneumonia. These cocci, all diplococci, possess the enzyme cytochrome $\mathrm{c}$ and consequently are oxidase positive.

Because the trace metals and fatty acids found in blood agar inhibit both neisseria species they are cultured on "chocolate" agar, a blood agar heated to $80^{\circ} \mathrm{C}$ to inactivate the inhibitors. Non-selective chocolate agar is used for usually sterile sites such as cerebrospinal fluid, blood, or synovial fluid. Thayer-Martin or Martin-Lewis selective media is used for sites where contamination of other bacterial flora is suspected, such as urethral cultures. The two major Neisseria spp can be differentiated from each other by carbohydrate utilisation tests.

Moraxella catarrhalis is one of the three main agents in acute otitis media and sinusitis besides $S$ pneumoniae and non-typable Haemophilus influenzae. Nearly $100 \%$ of strains of $M$ catarrhalis produce $\beta$-lactamases. Although amoxicillin remains an effective empiric therapy for acute otitis media, suspicion or isolation of $M$ catarrhalis warrants the addition of a $\beta$-lactamase inhibitor (that is, clavulonic acid).

\section{GRAM POSITIVE BACILLI}

Bacillus, clostridium, listeria, and corynebacterium are the four medically important genera of Gram positive rods (fig 4), with anaerobic growth differentiating the spore forming clostridium and bacillus while mobility differentiates the two non-spore forming Gram positive bacilli. Most Bacillus spp are nonpathogenic, but Bacillus anthracis is the cause of the disease anthrax while Bacillus cereus is a cause of food poisoning. Clostridium spp include the causative agents of gas gangrene, food poisoning, tetanus, botulism, and antibiotic associated colitis.

Listeria monocytogenes can be diagnosed by Gram stain alone with the appearance of Gram positive rods in small, grey colonies with a narrow zone of $\beta$-haemolysis resembling diphtheroids; it may be assumed to be a contaminant. Listeria monocytogenes is a common cause of infection in neonates and the immunocompromised and infection in pregnancy accounts for $27 \%$ of all cases of listerosis, usually occurring in the third trimester due to a decline in cell mediated immunity seen at 26-30 weeks' gestation. ${ }^{26}$ Because $L$ monocytogenes are uniformly not susceptible to cephalosporins, the practice of beginning ampicillin and cefotaxime as empiric neonatal sepsis coverage is questionable. Additionally, routine use of these antibiotics may contribute to cephalosporin resistance among strains of Enterobacter cloacae, Klebsiella spp, and Serratia spp in the nursery. ${ }^{27}$

Corynebacterium diphtheriae, the cause of diphtheria, are non-motile Gram positive rods with metachromatic granules, often arranged as "Chinese lettering" on Gram stain. A throat swab should be cultured on Löffler's medium 
to inhibit normal flora and enhance the metachromasia and a tellurite plate to highlight the reduction of tellurium salt in the organism. ${ }^{28}$ In patients with the clinical picture of tonsillopharygneal diphtheria characterised by a thick, grey, adherent membrane over the tonsils and throat the Gram stain can make the diagnosis as the methylene blue stain reveals the typical metachromatic granules.

\section{GRAM NEGATIVE BACILL}

Enteric tract

The family enterobacteriaceae, often called "enterics" due to their normal habitat in the colon of humans and animals, are differentiated by a range of biochemical tests but all fer- ment glucose (fermentation of other sugars varies), reduce nitrates to nitrites, and are oxidase negative (figs 5-7). Suspected enteric bacteria are inoculated on a blood agar plate as well as a selective medium such as MacConkey's agar or eosin-methylene blue agar to suppress unwanted Gram positive organisms by bile salts and bacteriostatic dyes. Lactose fermenters form coloured colonies while triple sugar iron agar, composed of ferrous sulfate and three sugars (glucose, fructose, and sucrose), determine fermentation as well as hydrogen sulphide production. Urea agar is used to determine urease production, which hydrolyses urea to ammonia and carbon dioxide and turns the $\mathrm{pH}$ alkaline.
Enterobacteriaceae

(catalase positive, oxidase negative,

nitrates reduced to nitrites, glucose fermented)

Non-enterobacteriaceae

Fermentative

Aeromonas

Pasteurella

Plesiomonas

Vibrio
Non-fermentative

Acinetobacter Alcaligenes

Burkholderia

Flavobacterium

Pseudomonas Stenotrophomonas Serratia Yersinia

Morganella

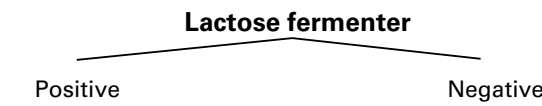

Escherichia coli Enterobacter aerogenes, cloacae Citrobacter (50\%)

Klebsiella pneumoniae

Vibrio vulnificus
Edwardsiella tarda Morganella morganii Pasteurella multocida Proteus mirabilis

Providencia Pseudomonas Salmonella typhi Serratia marcescens Shigella dysenteriae Vibrio cholerae, parahaemolyticus Yersinia pestis, enterocolitica, pseudotuberculosis

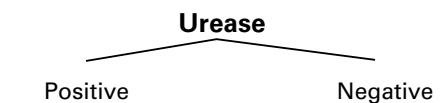

Citrobacter Klebsiella Morganella Proteus

Providencia

$Y$ enterocolitica

$Y$ pseudotuberculosis

Alcaligenes Eikenella corrodens

Pasteurella

Salmonella

Shigella

$Y$ pestis

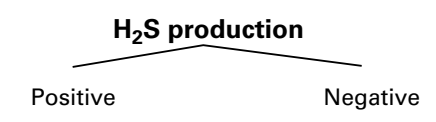

Citrobacter freundii Edwardsiella tarda $P$ vulgaris, mirabelis Salmonella pseudotuberculosis

Y

\begin{tabular}{|c|c|}
\hline \multicolumn{2}{|l|}{ Oxidase } \\
\hline Positive & Negative \\
\hline Aeromonas hydrophilia & Acinetobacter \\
\hline Alcaligenes & Klebsiella pneumoniae \\
\hline Burkholderia cepacia & Stenotrophomonas maltophilia \\
\hline Campylobacter jejuni, C fetus & \\
\hline Flavobacterium & \\
\hline Helicobacter pylori & \\
\hline Kingella kingae & \\
\hline Pasteurella multocida & \\
\hline Plesiomonas shigelloides & \\
\hline Pseudomonas aeruginosa & \\
\hline$V$ cholerae, $V$ parahaemolyticus & \\
\hline Figure 5 Differentiating aerobic & n negative bacilli. \\
\hline
\end{tabular}

\section{Citrobacter diversus Escherichia coli Klebsiella Morganella Providencia Serratia marcescens Shigella $Y$ pseudotuberculosis, enterocolitica}


Aerobic Gram negative coccobacilli Bartonella

Brucella melitensis

Bordetella pertussis

Campylobacter

Chlamydiae

Ehrlichia

Eikenella corrodens

Franciscella tularensis

Haemophilus influenzae

Helicobacter

Kingella

Bartonella

Legionella pneumonphila

Rickettsia

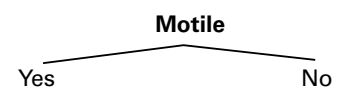

$\begin{array}{ll}\text { C jejuni } & \text { Bordetella pertussis } \\ \text { H pylori } & \text { Brucella melitensis } \\ \text { Legionella } & \text { Franciscella } \\ & \text { Haemophilus influenzae } \\ & \text { Kingella kingae }\end{array}$

Gamma
Hinfluenzae $\quad \begin{aligned} & \text { Bordetella pertussis } \\ & \text { Kingella kingae }\end{aligned}$

Figure 6 Differentiating aerobic Gram negative coccobacilli (including obligate intracellular).

A methylene blue stain of a fecal sample will determine whether polymorphonuclear cells (PMNs) are present. The presence of PMNs indicates the involvement of an invasive organism, such as shigella, salmonella, campylobacter, rather than a toxin-producing organism such as Vibrio cholerae, E coli, or Clostridium perfringens. Escherichia coli and salmonella produce disease both within and outside the enteric tract; in contrast, shigella, vibrio, campylobacter, and helicobacter produce disease primarily within the enteric tract.

Escherichia coli is the most abundant facultative anaerobe in the colon and faeces, although vastly outnumbered by the obligate anaerobe Bacteriodes fragilis, and the five major subdivisions each cause different clinical pictures. Escherichia coli O157:H7, famous in the public media for outbreaks of food poisoning, is so named by its antigens. The "O" or somatic antigen, is the outer polysaccharide portion of

\begin{tabular}{|c|c|c|c|}
\hline \multicolumn{2}{|l|}{ Cocci } & \multicolumn{2}{|l|}{ Bacilli } \\
\hline Gram positive & Gram negative & Gram positive & Gram negative \\
\hline $\begin{array}{l}\text { Peptococcus niger } \\
\text { Peptostreptococcus }\end{array}$ & Veillonella parvula & $\begin{array}{l}\text { Non-spore forming } \\
\text { Actinomyces israelii } \\
\text { Bifidobacterium } \\
\text { Eubacterium } \\
\text { Propionibacterium }\end{array}$ & $\begin{array}{l}\text { Bacteroides fragilis } \\
\text { Fusobacterium } \\
\text { Porphyromonus } \\
\text { Prevotella }\end{array}$ \\
\hline & & $\begin{array}{l}\text { Spore forming } \\
\text { Clostridium }\end{array}$ & \\
\hline
\end{tabular}
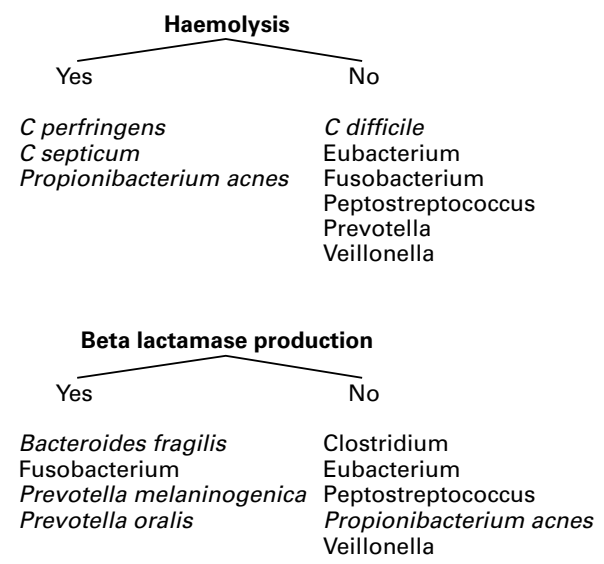

Figure 7 Differentiating anaerobic bacteria. the lipopolysaccharide; the " $\mathrm{H}$ " antigen is the flagellar antigen. In haemolytic uraemic syndrome $E$ coli $\mathrm{O} 157: \mathrm{H} 7$ produces a shiga-like verotoxin, named because it is toxic to Vero (African green monkey) cell culture. Escherichia coli $\mathrm{O} 157: \mathrm{H} 7$ is easily separated as it does not ferment sorbitol and forms pale colonies on sorbitol MacConkey agar.

Salmonella spp include the causes of typhoid and paratyphoid fevers, gastroenteritis, sepsis, and osteomyelitis, especially in patients with sickle cell disease. Unlike salmonella, shigella does not produce hydrogen sulphide gas (neither ferment lactose) and is immobile. Shigella produces bloody diarrhoea by invasion of the mucosa of the distal ileum and colon and is much more virulent than salmonella: as few as 100 organisms are necessary for disease as opposed to the 10000 organisms required with salmonella or $V$ cholerae. $^{29}$ More selective media such as xylose-lysine deoxycholate may be used to isolate shigella or salmonella from faecal specimens.

Five major non-enterobacteriacae also inhabit the enteric tract. Vibrio cholera causes cholera and is a comma shaped, oxidase positive Gram negative bacillus and its characteristic appearance can help make a presumptive diagnosis. Campylobacter are also comma or S shaped, oxidase positive, and often interpreted as coccobacilli on Gram stain. Campylobacter jejuni causes enterocolitis while Campylobacter intestinalis causes bacteraemia; the two are differentiated by nalidixic acid sensitivity. Helicobacter pylori, the cause of gastritis and peptic ulcer disease, is urease positive and may be demonstrated by Giemsa staining of gastric biopsies. Anaerobic Gram negative bacilli such as Bacteroides fragilis are abundant in the human colon whereas Fusobacterium spp and others are normal flora in the human oral cavity.

\section{Respiratory tract}

Of the six serotypes of $H$ influenzae (a-f), type b (Hib) causes the majority of invasive disease such as meningitis and epiglotitis. The $\mathrm{H} \mathrm{influ-}$ enzae species involved in acute otitis media and sinusitis are largely unencapsulated and, therefore, non-typable strains. The incidence of invasive $\mathrm{Hib}$ disease has declined dramatically since the introduction of the polyribosylribose phosphate vaccine in April 1985. Depending on local patterns, $10 \%$ to $40 \%$ of $H$ influenzae isolates produce $\beta$-lactamases. ${ }^{30}$ Latex particle agglutination for detection of capsular antigen in the cerebrospinal fluid is available, but antigen detection in the serum and urine can be unreliable due to asymptomatic nasopharyngeal carriage. Cultures of $H$ influenzae require the growth factors haemin (X) and/or nicotinamide adenine diphosphate $(\mathrm{V})$ provided by heated blood agar.

Legionella spp are bacilli that stain faintly Gram negative with the standard Gram stain and biopsy specimens do not stain with haematoxylin and eosin, requiring the use of the Dieterle silver impregnation stain. Because these organisms require high concentrations of iron and cysteine to grow, Legionella pneumophilia 
fails to grow on ordinary media and is cultured on buffered charcoal yeast extract medium or investigated directly by immunofluorescence. The majority of human disease is caused by $L$ pneumophilia serogroup 1 , which can be detected in the urine by radioimmunoassay, enzyme immunoassay, or serologically. ${ }^{31}$ Most species produce some $\beta$-lactamases.

Bordetella pertussis, the cause of whooping cough, occurs as Gram negative coccobacilli singly or in pairs. Bordetella pertussis can best be isolated from nasopharyngeal swabs (calcium alginate) obtained during the catarrhal stage when the organisms attach to the ciliated epithelium of the upper respiratory tract and cause decreased cilia activity and epithelial cell death. ${ }^{32}$ The special medium used for culture isolation in the past, Bordet-Gengou medium, has now been replaced with Regan-Lowe agar, a half strength charcoal agar with horse blood and cephalexin. ${ }^{33}$ Direct fluorescent antibody staining is also used, but is less sensitive than culture. No single serological test is diagnostic of pertussis. A profound leukocytosis, with up to $70 \%$ lymphoctes, can be seen. These are generally "typical" lymphocytes, as opposed to the classic "atypical" lymphocytes seen in Epstein-Barr virus infections.

Pseudomonas and related species include bacteria that are ubiquitous, some of which are important pathogens. Pseudomonas aeruginosa causes a wide variety of infections, including wound infections, urinary tract infections, and septicaemia. Pseudomonas aeruginosa is a nonlactose fermenter, oxidase positive, and isolates can be classified as smooth, rough, or mucoid based on their appearance on agar. The mucoid strains isolated from patients with cystic fibrosis produce alginate, a polysaccharide polymer with antiphagocytic activity. ${ }^{34}$ All psuedomonads have chormosomally encoded $\beta$-lactamases (not plasmid mediated) which are inducible and therefore may not be detectable in vitro until exposed to $\beta$-lactam antibiotics in vivo.

Recently there have been numerous taxonomic changes in the pseudomonas genus, creating the separate genera stenotrophomonas and burkholderia. Burkholderia cepacia (formerly Pseudomonas cepacia) is an increasingly important pathogen in patients with cystic fibrosis. It requires a unique agar for isolation and can be detected by its resistance to colistin. Stenotrophomonas maltophilia (formerly Xanthomonas maltophilia) is differentiated as oxidase negative. Virtually all isolates of $S$ maltophilia are resistant to penicillins, cephalosporins, and aminoglycosides and all are highly resistant to imipenem; trimethoprimsulfamethoxazole is the drug of choice.

The encapsulated Klebsiella pneumoniae historically has been recognised as the causative agent in pneumonia characterised by thick, bloody "currant-jelly" sputum. Serratia marcescens produces a striking red pigment, and it and Enterobacter cloacae are often nosocomial infections related to invasive procedures. Previously four species were classified as proteus, however two of these have been renamed Providencia rettgeri and Morganella morganii. All three genera are urease positive and a common cause of urinary tract infections. Proteus spp are characterised by their ability to "swarm" on blood agar plates.

\section{Zoonotic}

Because of the risks that the major zoonotic bacteria such as Brucella spp, Francisella tularensis, Yersinia pestis, and Pasteurella multocida pose to laboratory personnel they are seldom cultured; consequently, diagnosis is made serologically. Brucella melitensis, the agent in what was originally known as Malta fever, is localised in the reticuloendothelial system where it survives within macrophages as a facultative intracellular parasite. Tularaemia (rabbit fever or deer fly fever) is an infection caused by Francisella tularensis. Humans often serve as accidental hosts who acquire infection after bitten by a dermacentor tick or removing the hide of an infected animal. Yersinia pestis is the encapsulated organism responsible for the "plague," and Yersinia enterocolitica mimics appendicitis. Laboratory identification of yersinia in stool can be made by characteristic "safety-pin" bipolar appearance in Wayson's stain, the use of fluorescent antibody testing, or serological testing with passive haemagglutination or enzyme immunoassay. ${ }^{35}$ Pasteurella multocida is part of the normal oral flora of domestic cats and dogs and is may cause infection in bite wounds.

SPIROCHETES

Spirochetes are spiral, motile organisms that are not easily cultivated in the routine laboratory. The three genera of importance are borrelia, treponema, and leptospira. Borrelia burgdorferi causes Lyme disease, while Borrelia recurrentis and Borrelia hermsii cause relapsing fever, so named for its anitgenic variation during relapses of the illness. Diagnosis of Lyme disease is made with serological tests, most commonly enzyme immunoassay, and due to the concern for cross reactivity with other spirochetal antibodies a second step using western immunoblot is now advocated for verification of enzyme immunoassay results. ${ }^{36}$ Cultures for $B$ burgdoferi are rarely positive, but culture of the organism from the tick vector is usually positive. Borrelia recurrentis can be seen in Giemsa stains of blood films from infected patients.

Treponema pallidum, the cause of syphilis, may be identified as tightly wound spirochetes using dark field microscopy since only nonpathogenic treponemes have ever been grown in culture. Generally serological tests are used in the diagnosis of syphilis with nontreponemal antigens such as cardiolipin from beef heart reacting with serum antibodies (called reagins). Flocculation tests like the Venereal Disease Research Laboratory and rapid plasma reagin detect these antibodies. Treponema pallidum in treponemal specific tests react with immunofluorescence in the fluorescent treponemal antibody absorbed test or haemagglutination in the microtitre haemagglutination assay $T$ pallidum. Whereas a nontreponemal test usually becomes non-reactive 
after successful therapy, treponemal tests remain reactive for life despite successful therapy.

Leptospira interrogans, the cause of leptospirosis, is occasionally isolated from blood and urine in special cultures, but diagnosis is made through a marked rise in enzyme immunoassay or agglutination antibodies.

\section{OBLIGATE INTRACELLULAR ORGANISMS}

These bacteria lack some of the mechanism for production of energy and therefore grow only inside host cells. Their cell walls resemble Gram negative bacteria, but lack muramic acid. Chlamydia trachomatis is the most common chlamydiae pathogen and new nucleic acid amplification using ligase chain reactions is more sensitive than cell culture and detects antigen in the urine.$^{37}$ Diagnosis of rickettsiae is usually made serologically and Rocky Mountain spotted fever (Rickettsia rickettsii) is best detected through indirect fluorescent antibody and indirect haemagglutination, but antibodies are detected 7-10 days after illness. No microbiological test is readily available for rapid diagnosis early in the illness; the polymerase chain reaction has been used during the acute phase. This test, while specific, is insensitive and performs only slightly better on skin biopsies than blood specimens. ${ }^{38}$

ORGANISMS WITH NO CELL WALL

Mycoplasmas are small, non-motile, freeliving organisms that lack a cell wall, which means there are no Gram stain results and antibiotics that inhibit cell wall synthesis (for example, penicillins and cephalosporins) are ineffective. The majority of infections caused by $\mathrm{Myco}-$ plasma pneumoniae include pneumonia and tracheobronchitis, while Mycoplasma hominis can cause urethritis, postpartum infection, and pelvic inflammatory disease. Mycoplasmas are slow growing so diagnosis is made serologically. In children cold agglutinins, immunoglobulin $\mathrm{M}$ autoantibodies against type $\mathrm{O}$ red blood cells that agglutinate at $4^{\circ} \mathrm{C}$ but not at $37^{\circ} \mathrm{C}$, are not as reliable as in adults. Ureaplasma can be distinguished from mycoplasma by its ability to produce urease.

\section{Conclusion}

The clinical bacteriology laboratory can be pivotal in guiding clinicians to make a rapid diagnosis and initiate appropriate treatment. The Gram stain is the microbiologists' century old quintessential first line diagnostic tool allowing preliminary identification of bacteria. Housestaff physicians should receive formal training in the interpretation of the Gram stain and other basic clinical bacteriological tests. A more rigorous and confident use of clinical microbiological knowledge may allow greater precision in diagnosis and focused narrow spectrum antibiotic treatment, thus curbing the growing trend of inappropriate antibiotic use in the current era of increased antimicrobial resistance.

1 Friedlander C. Die Mikrokokken der Pneumonie. Fortschr Med 1883;1:715-33.
2 Gram C. Uber die isolirte Farung der Schizomycetin in Schnitt-und Trockenpraparaten. Fortschr Med 1884;2:1859

3 Bartholomew JW. Variables influencing results and the precise definition of steps in gram staining as a means of standardizing the results obtained. Stain Technol 1962;37:139-55.

4 Bartholomew JW, Mittwer T. The Gram stain. Bacteriol Rev 1952;16:1-29.

5 Bottone EJ. The Gram stain: the century-old quintessential rapid diagnostic test. Lab Med 1988;19:288-91.

6 Mandel LP, Schaad DC, Cookson BT, et al. Evaluation of an interactive computer program to teach Gram-stain interactive computer program to teach Gram-st
interpretation. Acad Med 1996;71 (10 suppl):S100-2.

7 Popescu A, Doyle RJ. The Gram stain after more than a century. Biotech Histochem 1996;71:145-51.

8 Biswas BB, Basu PS, Pal MK. Gram staining and its molecular mechanism. Int Rev Cytol 1970;29:1-27.

9 Joklik WK, Willett HP, Amos DB, et al. Staphylococcus. In: Joklik WK, Willet HP, Amos DB, et al, eds. Zinsser microbiology. 20th Ed. East Norwalk, CT: Appleton \& Lange, 1992: 401-16.

10 Wilkinson BJ. Biology. In: Crossley KB, Archer GL, eds. The staphylococci in human disease. New York: Churchillstaphylococci in human

11 Maranan MC, Moreira B, Boyle-Vavra S, et al. Antimicrobial resistance in staphylococci. Epidemiology, molecular mechanisms, and clinical relevance. Infect Dis Clin North Am 1997;11:813-49.

12 Barrett FF, McGehee RF, Finland M. Methicillin-resistant Staphylococcus aureus at Boston City Hopsital. N Engl f Med 1968;279:441-8.

13 Archer G, Niemeyer DM. Origin and evolution of DNA associated with resistance to methicillin in staphylococci. Trends Microbiol 1994;2:343-7.

14 Centers for Disease Control and Prevention. Staphylococcus aureus with reduced susecptibility to vancomycinUnited States, 1997. MMWR Morb Mortal Wkly Rep1997; 46:813-15.

15 Joklik WK, Willett HP, Amos DB, et al. Streptococcus. In: Joklik WK, Willet HP, Amos DB, et al, eds. Zinsser microbiology. 20th Ed. East Norwalk, CT: Appleton \& Lange, 1992: 417-31.

16 Pichichero, ME. Group A beta-hemolytic streptococcal infections. Pediatr Rev 1998;19:291-302.

$17 \mathrm{Kim} \mathrm{KS}$. Clinical perspectives on penicillin tolerance. $\mathcal{f}$ Kim KS. Clinical perspecti
Pediatr 1988;112:509-14.

18 Christie R, Atkins NE, Munch-Peterson E. A note of a lytic phenomenon shown by group B streptococci. Aust $\mathcal{F}$ Exp Biol Med Sci 1944;22:197-200.

19 Baker CJ, Edwards MS. Streptococcus agalactiae (group B streptococcus). In: Long SS, Pickering LK, Prober CG, eds. Principles and practice of pediatric infectious diseases. New York: Churchill-Livingstone, 1997: 812-18.

20 Haslam DB, St Geme III JW. Viridans streptococci, nutritionally variant streptococci, and Streptococcus bovis. nutritionally variant streptococci, and Streptococcus bovis.
In: Long SS, Pickering LK, Prober CG, eds. Principles and practice of pediatric infectious diseases. New York: Churchillpractice of pediatric infection
Livingstone, 1997: 821-3.

21 Starke JR. Infective endocarditis. In: Feigin RD, Cherry JD, eds. Textbook of pediatric infectious diseases. 4th Ed. Philadelphia: WB Saunders, 1998: 315-38.

22 English BK, Shenep JL. Enterococcal and viridans streptococcal infections. In: Feigin RD, Cherry JD, eds. Textbook of pediatric infectious diseases. 4th Ed. Philadelphia: WB Saunders, 1998: 1106-20.

23 American Academy of Pediatrics Committee on Infectious Diseases. Therapy for children with invasive pneumococcal Diseases. Therapy for children with inve
infections. Pediatrics 1997;99:289-99.

24 Dowell SF, Butler JC, Giebink S, et al. Acute otitis media: management and surveillance in an era of pneumococcal resistance - a report from the drug-resistant Streptococcus pneumoniae Therapeutic Working Group. Pediatr Infect Dis f 1999;18:1-9.

25 Willoughby R, Polack F. Meningitis: what's new in diagnosis and management. Contemp Pediatr 1998;15:49-70.

26 Lorber B. Listeria monocytogenes. In: Long SS, Pickering LK, Prober CG, eds. Principles and practice of pediatric infecLK, Prober CG, eds. Principles and practice of pediatric infec-
tious diseases. New York: Churchill-Livingstone, 1997: tious diseas 873 .

27 American Academy of Pediatrics. Escherichia coli and other Gram-negative bacilli. In: Peter G, ed. 1997 Red book: report of the Committee on Infectious Diseases. 24th Ed. Elk Grove Village, IL: American Academy of Pediatrics, 1997: 202-4.

28 Levinson WE, Jawetz E. Corynebacterium diphtheriae. In: Levinson WE, Jawetz E, eds. Medical microbiology \& immunology. 3rd Ed. Norwalk, CT: Appleton \& Lange, 1994: 84-6.

29 Levinson WE, Jawetz E. Shigella. In: Levinson WE, Jawetz E, eds. Medical microbiology \& immunology. 3rd Ed. Norwalk, CT: Appleton \& Lange, 1994: 96.

30 American Academy of Pediatrics. Haemophilus influenzae infections. In: Peter G, ed. 1997 Red book: report of the Committee on Infectious Diseases. 24th Ed. Elk Grove Village, IL: American Academy of Pediatrics, 1997: 220-31.

31 American Academy of Pediatrics. Legionella pneumophilia infections. In: Peter G, ed. 1997 Red book: report of the Committee on Infectious Diseases. 24th Ed. Elk Grove Village, IL: American Academy of Pediatrics, 1997: 319-21.

32 Levinson WE, Jawetz E. Bordetella. In: Levinson WE, Jawetz E, eds. Medical microbiology \& immunology. 3rd Ed. Norwalk, CT: Appleton \& Lange, 1994: 108-9. 
33 Joklik WK, Willett HP, Amos DB, et al. Bordetella. In: Joklik WK, Willet HP, Amos DB, et al, eds. Zinsser microbiology. 20th Ed. East Norwalk, CT: Appleton \& Lange, 1992: 473 80.

34 Brady MT, Feigin RD. Pseudomonas and related species. In: Feigin RD, Cherry JD, eds. Textbook of pediatric infectiou diseases. 4th Ed. Philadelphia: WB Saunders, 1998: 140113.

35 American Academy of Pediatrics. Plague. In: Peter G, ed. 1997 Red book: report of the Committee on Infectious Diseases. 24th Ed. Elk Grove Village, IL: American Academy of Pediatrics, 1997: 408-10.
36 American Academy of Pediatrics. Lyme disease. In: Peter G, ed. 1997 Red book: report of the Committee on Infectious of Pediatrics, 1997: 329-33.

37 American Academy of Pediatrics. Chlamydia trachomatis In: Peter G, ed. 1997 Red book: report of the Committee on Infectious Diseases. 24th Ed. Elk Grove Village, IL: American Academy of Pediatrics, 1997: 170-4.

38 American Academy of Pediatrics. Rocky Mountain spotted fever. In: Peter G, ed. 1997 Red book: report of the Committee on Infectious Diseases. 24th Ed. Elk Grove Village, IL: American Academy of Pediatrics, 1997: 452-6. 